\title{
TOMBAMENTO DE MUDAS DE ESPÉCIES FLORESTAIS CAUSADO POR Sclerotium rolfsii Sacc. ${ }^{1}$
}

\author{
Reginaldo Gonçalves Mafia ${ }^{2}$, Acelino Couto Alfenas ${ }^{3}$ e Márcio Fernando Ribeiro de Resende Júnior ${ }^{4}$
}

\begin{abstract}
RESUMO - O estudo objetivou avaliar a gama de hospedeiros de Sclerotium rolfsii por inoculação controlada das seguintes espécies florestais nativas e exóticas: Anadenanthera peregrina (angico-vermelho), Chorisia speciosa (paineira-rosa), Clitoria fairchildiana (sombreiro), Copaifera langsdorffii (copaíba), Delonix regia (flamboyant-vermelho), Enterolobium contortisiliquum (orelha-de-negro), Leucaena leucocephala (leucena), Mabea fistulifera (canudo-de-pito), Platymiscium pubescens (tamboril-da-mata), Senna macranthera (fedegoso), Spathodea campanulata (espatódea) e Tabebuia avellanedae (ipê-roxo), bem como comprovar o tombamento de mudas em pré e pós-emergência. Todas as espécies foram suscetíveis ao tombamento de mudas causado por $S$. rolfsii, em pré e em pós-emergência.
\end{abstract}

Palavras-chave: Tombamento de mudas, viveiro e Sclerotium rolfsii.

\section{DAMPING-OFF OF FOREST SPECIES CAUSED BY Sclerotium rolfsii Sacc.}

\begin{abstract}
The host range of Sclerotium rolfsii was evaluated by controlled inoculation of the following native and exotic forest species: Anadenanthera peregrina (angico vermelho), Chorisia speciosa (paineira rosa), Clitoria fairchildiana (sombreiro), Copaifera langsdorffii (copaíba), Delonix regia (flamboyant vermelho), Enterolobium contortisiliquum (orelha de negro), Leucaena leucocephala (leucena), Mabea fistulifera (canudode-pito), Platymiscium pubescens (tamboril da mata), Senna macranthera (fedegoso), Spathodea campanulata (espatódea) e Tabebuia avellanedae (ipê roxo). The fungus caused damping-off in pre and post emergence in all tested species.
\end{abstract}

Keywords: Damping-off seedlings, nursery and Sclerotium rolfsii.

\section{INTRODUÇÃO}

No Brasil, a produção de mudas de espécies florestais nativas, com algumas exceções, ainda é realizada em viveiros dotados de baixa tecnologia, sem o emprego de manejo adequado para o controle de doenças, conforme é realizado para o eucalipto (ALFENAS et al., 2004). Além disso, com a proibição do emprego de brometo de metila, exceto para tratamento fitossanitário até 2015 e para fins especiais de pesquisa, por afetar a camada de ozônio (ALBREGTS et al., 1996), a desinfestação de substratos para a produção de mudas ficou comprometida, em virtude da falta de um produto de igual eficiência. Nesse caso, a incidência de doenças, como o tombamento de mudas, tende a se tornar ainda mais importante.

O tombamento de mudas ocorre em pré ou pósemergência. O primeiro caso é caracterizado quando o ataque do patógeno resulta na morte da semente ou da semente em germinação, ainda em pré-emergência, muitas vezes confundido com a baixa capacidade de

\footnotetext{
${ }^{1}$ Recebido em 19.12.2006 e aceito para publicação em 29.03.2007

${ }^{2}$ Departamento de Fitopatologia da Universidade Federal de Viçosa. Viçosa- MG 36570-000. E-mail: <rgoncalves@aracruz.com.br> e<aalfenas@ufv.br>.

${ }^{3}$ Departamento de Biologia da UFV. Viçosa-MG 36570-000. E-mail: <marciopac@ hotmail.com>.
} 
germinação. Já o tombamento em pós-emergência se caracteriza pelo anelamento do coleto ou de porções superiores da haste da plântula ou planta, a qual murcha e tomba sobre o substrato (ALFENAS et al., 2004; AUER et al., 2001; FERREIRA, 1989).

Entre os patógenos que causam o tombamento de mudas, o fungo Sclerotium rolfsii Sacc. destacase em virtude de sua ampla gama de hospedeiros, que abrange aproximadamente 500 espécies botânicas, sua alta capacidade de sobrevivência no solo e ampla distribuição geográfica, predominantemente nas zonas tropical e subtropical, sob condições de alta umidade e temperatura elevada (AYCOCK, 1966; PUNJA e JENKINS, 1984; PUNJA, 1985; PUNJA e RAHE, 1992).

No Brasil, dentre as espécies florestais, $S$. rolfsii foi constatado em Araucaria excelsa R. Br., Cryptomeria japonica D. Don, Joanesia princeps Vell., Tabebuia serratifolia Nichols. (FERREIRA, 1989; MENDES et al., 1998) e em Azadirachta indica A. Juss (SILVA, 1996; MENDES et al., 1998). Todavia, S. rolfsii pode, potencialmente, afetar qualquer espécie florestal nos viveiros (FERREIRA, 1989). Nesse sentido, este trabalho objetivou avaliar a gama de hospedeiros de $S$. rolfsii, como potencial agente etiológico do tombamento de mudas em pré e pós-emergência.

\section{MATERIAL E MÉTODOS}

\subsection{Material vegetal}

As sementes utilizadas nesta pesquisa foram obtidas do Setor de Silvicultura pertencente ao Departamento de Engenharia Florestal (DEF) da Universidade Federal de Viçosa. As sementes foram colhidas em 2004 e armazenadas conforme a rotina do Laboratório de Análise de Sementes Florestais (LASF). Utilizaram-se as seguintes espécies florestais: Anadenanthera peregrina (L.) Speg (angicovermelho), Chorisia speciosa St. Hil. (paineira-rosa), Clitoria fairchildiana R.A. How ard (sombreiro), Copaifera langsdorffii Desf (copaíba), Delonix regia (Hook.) Raf. (framboyant-vermelho), Enterolobium contortisiliquum (Vell.) Morong (orelha-de-negro), Leucaena leucocephala (Lam.) de Wil (leucena), Mabea fistulifera Mart. (canudo-de-pito), Platymiscium pubescens Micheli (tamboril-da-mata), Senna macranthera (Dc. ex Collad.) H.S. Irwin \& Barneby (fedegoso), Spathodea campnulata Beauv. (espatódea) e Tabebuia avellanedae Lor ex Griseb. (ipê-roxo).

R. Árvore, Viçosa-MG, v.31, n.4, p.629-634, 2007
As mudas utilizadas para inoculação foram obtidas a partir da semeadura em caixas plásticas (27 x 38 x $10 \mathrm{~cm}$ ) contendo uma mistura de solo, areia e esterco bovino (4:1:2), enriquecida com $1 \mathrm{~g} / \mathrm{l}$ de superfosfato simples, previamente esterilizada. A esterilização foi realizada com brometo de metila $\left(150 \mathrm{cc} / \mathrm{m}^{3}\right.$ da mistura), mediante autorização especial para uso em pesquisa. Antes da semeadura, realizou-se a quebra de dormência das sementes de copaíba (imersão das sementes em água fria por $24 \mathrm{~h}$ ), fedegoso (imersão das sementes em ácido sulfúrico $98 \%$ por $20 \mathrm{~min}$ ), flamboyantvermelho (imersão das sementes em água a $100^{\circ} \mathrm{C}$ por $1 \mathrm{~min}$ ), leucena (imersão das sementes em ácido sulfúrico $98 \%$ por $20 \mathrm{~min}$ ) e orelha-de-negro (imersão das sementes em ácido sulfúrico $98 \%$ por $30 \mathrm{~min}$ ), conforme recomendado por Carvalho (1994), Durigan et al. (1997), Lorenzi (2002 ab) e Lorenzi et al. (2003). As sementeiras foram mantidas em câmara de crescimento a $28 \pm 2{ }^{\circ} \mathrm{C}$, umidade relativa de $80 \%$ $\pm 5 \%$, luminosidade de $36 \mathrm{mmol} . \mathrm{m}^{-2} \cdot \mathrm{s}^{-1}$ e fotoperíodo de $12 \mathrm{~h}$.

\subsection{Obtenção do isolado, produção de inóculo e inoculação}

O isolado de $S$. rolfsii (LPF-05) empregado no estudo foi obtido pelo isolamento direto a partir de plantas de angico-vermelho (Anadenanthera peregrina L.) com sintomas de tombamento de mudas em pósemergência, coletadas no viveiro de pesquisa do DEF. Para realizar o isolamento, escleródios do patógeno, coletados na região do coleto das plantas, foram desinfestados, superficialmente, em álcool $70 \%$ por 30 s e em hipoclorito de sódio (5\%) por 3 min e, a seguir, enxaguados em água destilada esterilizada. Após a desinfestação e remoção do excesso de hipoclorito de sódio, os escleródios foram transferidos, assepticamente, para placas de Petri contendo batatadextrose-ágar (BDA). As placas foram mantidas a 27 ${ }^{\circ} \mathrm{C}$, no escuro, quando se realizou a transferência das culturas puras do patógeno para tubos de ensaio contendo BDA inclinado. Após cinco dias de incubação, nas mesmas condições descritas anteriormente, as culturas foram armazenadas em geladeira $\left(10^{\circ} \mathrm{C}\right)$.

Para produção de inóculo do patógeno, realizouse a transferência de porções de uma das colônias armazenadas em tubos de ensaio para placas de Petri contendo BDA, as quais foram mantidas por cinco dias, a temperatura de $27^{\circ} \mathrm{C}$, com fotoperíodo de $12 \mathrm{~h}$. 
As plantas foram inoculadas por deposição de discos ( $5 \mathrm{~mm}$ de diâmetro) de cultivo do fungo, obtidos a partir das colônias crescidas em BDA, sobre o coleto. Plantas com deposição de discos de BDA sem o fungo foram utilizadas como testemunhas, enquanto a inoculação com discos contendo o fungo sobre o coleto de plantas de angico-vermelho, previamente reconhecidas como suscetíveis, foi empregada como controle positivo.

As avaliações foram realizadas diariamente, observando-se o surgimento de alterações na coloração, consistência e colonização fúngica das porções basais das mudas inoculadas, bem como o tombamento propriamente dito, em relação à testemunha e ao controle positivo de suscetibilidade. As mudas com sintomas da doença foram coletadas e levadas ao laboratório para isolamento pelo método indireto. Para isso, fragmentos de aproximadamente $0,5 \mathrm{~cm}$, retirados do coleto das plantas, foram desinfestados superficialmente e transferidos, assepticamente, para placas de Petri contendo BDA, seguido de incubação nas mesmas condições descritas anteriormente, de forma a reisolar o agente etiológico da doença e, assim, confirmar a patogenicidade.

\subsection{Determinação da taxa de germinação}

Para cada lote de semente, determinou-se, previamente, o índice de germinação, empregando-se o teste em papel-filtro. Sementes de cada uma das espécies foram dispostas eqüidistantes entre si sob duas folhas de papel-filtro umedecidas e esterilizadas, contidas em recipiente do tipo caixa plástica gerbox ( 11 x 11 x $3 \mathrm{~cm}$ ) com tampa translúcida. Sobre as sementes depositou-se uma folha de papel-filtro umedecida e esterilizada. Para cada espécie, empregaram-se cinco repetições, cada uma constituída de um gerbox contendo 10 sementes. Sementes de copaíba, fedegoso, flamboyantvermelho, leucena e orelha-de-negro foram submetidas à quebra de dormência, conforme descrito anteriormente, antes da realização do teste de germinação. As sementes foram incubadas em germinador do tipo BOD, a $25^{\circ} \mathrm{C}$, fotoperíodo de $12 \mathrm{~h}$ e durante 25 dias. Diariamente, realizou-se a contagem do número de sementes germinadas em relação ao total.

\subsection{Constatação do tombamento de mudas}

Para comprovação do tombamento de mudas em pré e pós-emergência, empregaram-se escleródios do patógeno como inóculo inicial. Para produção dos escleródios, cultivou-se o patógeno em BDA por 15 dias, a $27^{\circ} \mathrm{C}$, sob fotoperíodo de $12 \mathrm{~h}$. Os escleródios, produzidos sobre a massa micelial, foram recolhidos com o auxílio de um pincel de cerdas macias. Antes da montagem do ensaio, avaliou-se a taxa de germinação dos escleródios no mesmo meio de cultivo e sob as mesmas condições de incubação. Os escleródios foram misturados em vermiculita esterilizada de granulometria média, com umidade ajustada para 200\% (base seca), em caixas do tipo gerbox, na proporção de 0,2 escleródios/ g de vermiculita umedecida. Após a infestação, as sementes foram misturadas com a vermiculita, e todo o material foi incubado a $28^{\circ} \mathrm{C}$, no escuro, por $96 \mathrm{~h}$. Após esse período, as sementes foram retiradas e separadas da vermiculita e dos escleródios, por peneiramento, seguindo da quebra de dormência das sementes de copaíba, fedegoso, flamboyant-vermelho, leucena e orelha-de-negro, conforme descrito anteriormente. Após esses procedimentos, as sementes foram postas a germinar em sementeiras preenchidas com substrato à base de composto de casca de pinus (Plantmaxâ). Como testemunha, empregaram-se sementes previamente incubadas em mistura com vermiculita estéril. As sementeiras foram mantidas em câmara de crescimento a $28 \pm 2{ }^{\circ} \mathrm{C}$, umidade relativa de $80 \% \pm$ $5 \%$ e luminosidade de $36 \mathrm{mmol} \cdot \mathrm{m}^{-2} \cdot \mathrm{s}^{-1}$, com fotoperíodo de 12 h. Após 30 dias, as sementes não germinadas e as plantas foram retiradas e incubadas sob duas folhas de papel-filtro umedecida, contida em caixa do tipo gerbox, a $27^{\circ} \mathrm{C}$, no escuro, por sete dias. Diariamente, avaliou-se, sob binocular estereoscópica, a presença de sinais de $S$. rolfsii.

\section{RESULTADOS E DISCUSSÃO}

\subsection{Suscetibilidade das espécies florestais nativas e exóticas}

Cerca de 3-5 dias após a inoculação, observouse o desenvolvimento de lesões escuras a partir do coleto e murcha, decorrente no anelamento, seguido do tombamento das plântulas de todas as espécies avaliadas, assim como observado em plantas de angicovermelho (Figuras $1 \mathrm{~A}-\mathrm{C}$ ). Além disso, constatou-se a presença de abundante micélio branco, numerosos e diminutos escleródios esféricos, típicos de $S$. rolfsii. A partir do reisolamento utilizando-se fragmentos retirados do coleto das plântulas, ocorreu o desenvolvimento de micélio branco vigoroso, com formação de escleródios marrons de 1-2 mm de diâmetro (Figura 1 D),

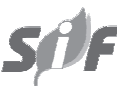

R. Árvore, Viçosa-MG, v.31, n.4, p.629-634, 2007 
especialmente a partir de cinco dias de cultivo a 27 ${ }^{\circ} \mathrm{C}$, comprovando a patogenicidade de $S$. rolsii às diferentes espécies florestais avaliadas. Sabe-se que o fungo apresenta extensa gama de hospedeiros, com cerca de 500 espécies botânicas, incluindo monocotiledôneas e dicotiledôneas (AYCOCK, 1966; PUNJA e JENKINS, 1984; PUNJA, 1985; PUNJA e RAHE, 1992). Esse patógeno pode, potencialmente, afetar qualquer espécie florestal em viveiro, sendo favorecido pela presença de alta umidade e temperaturas variando de moderada à alta (FERREIRA, 1989). Essas condições são comuns em viveiros florestais, nos quais é comum a realização de freqüentes irrigações e o adensamento de mudas, visando minimizar o consumo de água e de insumos.

\subsection{Constatação do tombamento de mudas}

A porcentagem de germinação das sementes previamente incubadas na presença do patógeno foi inferior à daquela determinada in vitro, pelo teste de germinação em papel-fitro, à exceção de copaíba. A maior germinação in vivo dessa espécie deveu-se, provavelmente, ao maior tempo de condução do experimento em relação à determinação da germinação no teste em papel-filtro. A diferença entre os valores reais e determinados em laboratório em parte ocorreu devido ao tombamento de mudas em pré-emergência (Quadro 1), o que deve ser somado ao efeito de outros fatores que podem ter afetado a germinação das sementes. Platymiscium pubescens Micheli foi mais afetada pela doença, considerando o tombamento em pré e pósemergência. A semente dessa espécie é formada em frutos do tipo vagem, que podem ser considerados como as próprias "sementes" para fins práticos de semeadura (LORENZI, 2002), conforme realizado neste estudo. Nesse sentido, acredita-se que a maior incidência da doença nessa espécie seja explicada pela maior quantidade de tecido vegetal disponível para colonização do patógeno.

O tombamento de mudas, quando ocorre em préemergência, muitas vezes é considerado, indevidamente, como efeito da baixa qualidade do lote de sementes, quando não se conhece a real porcentagem de germinação. Isso foi demonstrado, principalmente, para Enterolobium contortisiliquum (Vell.) Morong, com aproximadamente $77 \%$ das sementes sem germinação devido a essa doença.
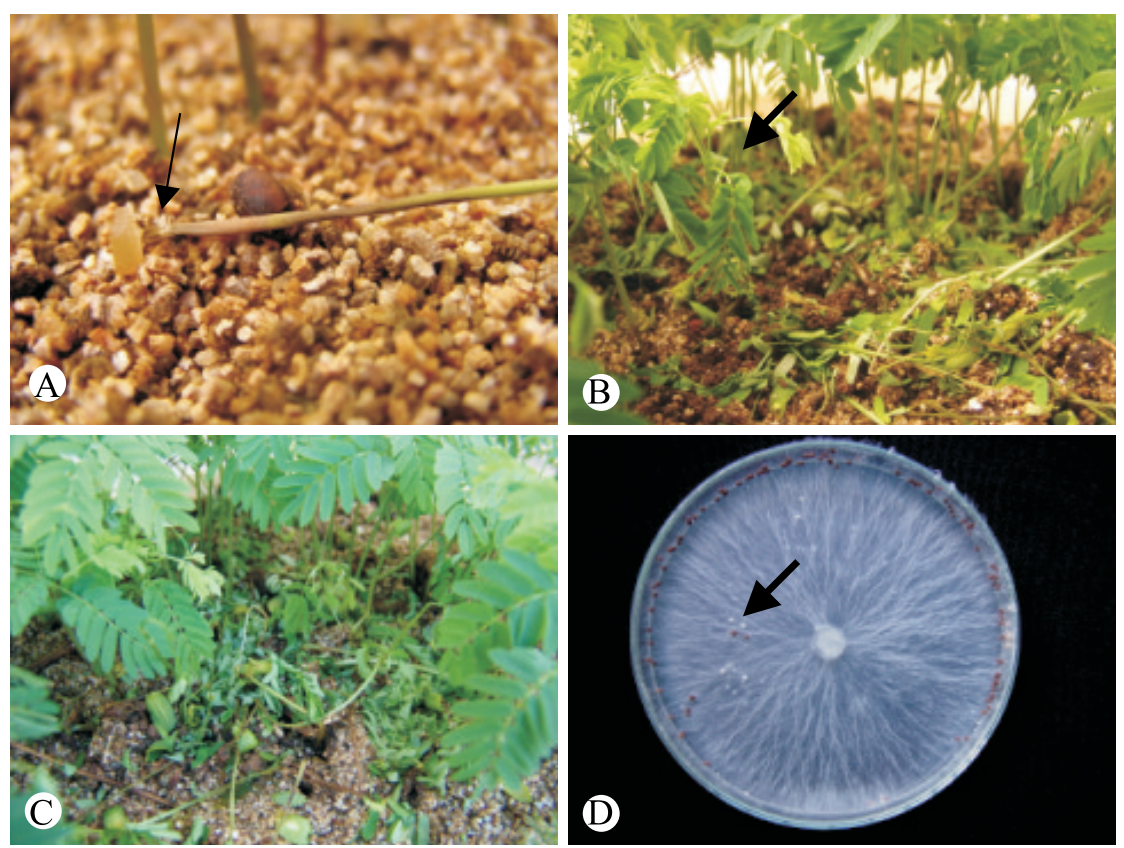

Figura 1 - (A) e (B) Tombamento de mudas de Anadenanthera peregrina causado por Sclerotium rolfsii, (C) Sementeira com tombamento de mudas e (D) Cultura típica do patógeno.

Figure 1 - (A) and (B) Damping-off on seedlings of Anadenathera peregrina caused by Sclerotium rolfsii; (C) Seedbed with seedlings damping-off; (D) Typical culture of the pathogen.

R. Árvore, Viçosa-MG, v.31, n.4, p.629-634, 2007

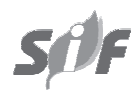


Quadro 1 - Taxa de germinação (A), germinação em substrado infestado (B) e tombamento de mudas em pré (C) e pós-emergência (D)

Table 1 - Germination rate $(A)$, germination in infested substrate $(B)$, and damping-off of seedlings in pre $(C)$ and post emergence $(D)$

\begin{tabular}{lcccc}
\hline \multicolumn{1}{c}{ Espécie } & $\mathrm{A}$ & $\mathrm{B}$ & \multicolumn{2}{c}{ Tombamento(\%) } \\
\cline { 5 - 6 } & $(\%)$ & $(\%)$ & $\mathrm{C}$ & $\mathrm{D}$ \\
\hline Chorisia speciosa & 72,0 & 60,0 & 35,0 & 30,0 \\
Clitoria fairchildiana & 14,0 & 4,0 & 27,6 & 100 \\
Copaifera langsdorffii & 60,0 & 100 & 0,0 & 26,0 \\
Delonix regia & 56,0 & 52,0 & 33,3 & 50,0 \\
Enterolobium & 94,0 & 48,0 & 76,9 & 16,6 \\
contortisiliquum & & & & \\
Leucaena leucocephala & 98,0 & 40,0 & 23,3 & 65,0 \\
Mabea fistulifera & 64,0 & 22,0 & 17,9 & 36,3 \\
Platymiscium & 16,0 & 12,2 & 76,7 & 100 \\
pubescens Micheli & & & & \\
Senna macranthera & 78,0 & 31,4 & 29,1 & 36,3 \\
Spathodea campanulata & 30,0 & 16,0 & 4,7 & 12,5 \\
Tabebuia avellanedae & 28,0 & 14,0 & 2,0 & 0,0 \\
\hline
\end{tabular}

S. rolfsii colonizou as sementes, pelo menos, externamente. Além dessa forma de associação, sabese que escleródios do patógeno ou fragmentos de micélio saprófitico podem estar misturados no lote de sementes, dependendo do processo de beneficiamento. $S$. rolfsii é um fungo de solo, que na ausência de hospedeiros sobrevive por meio de escleródios e pelo crescimento micelial saprofítico (PUNJA, 1985). Em virtude da maior facilidade operacional, sementes de espécies florestais podem, muitas vezes, ser coletadas no chão, o que deve ser evitado, a fim de minimizar os riscos de contaminação do lote de sementes.

Considerando as demais fontes iniciais de inóculo, é importante considerar a utilização de substratos inertes e isentos de patógenos. Atualmente, com a proibição da utilização do brometo de metila para fins de fumigação e na falta de outro produto de igual eficiência, temse buscado alternativas para esterilização de substratos de produção de mudas, como a pasteurização e solarização (ALBREGTS et al., 1996; CHEN e KATAN, 1980; MARTINS, et al., 2003; GHINI e BETTIOL, 1991; GHINI, 1993; KATAN, 1980, 1981; LIFSHITZet al., 1983). Todavia, nesses casos é necessário considerar os efeitos sobre as propriedades do solo e sobre o crescimento das plantas (RISTAINO et al., 1996), bem como a eficiência do método, que dependerá, por exemplo, das temperaturas alcançadas, do tipo de substrato e do teor de umidade. Além disso, é necessário considerar os efeitos sobre microrganismos benéficos, incluindo os antagonistas de fitopatógenos e simbiontes (MARTINS et al., 2003).

A água de irrigação deve ser coletada em poços artesianos ou preferencialmente tratada, enquanto os recipientes de produção de mudas devem ser esterilizados, utilizando-se, por exemplo, água quente (ALFENAS et al., 2004). Essas medidas preventivas de controle somado ao manejo adequado das mudas, quanto à nutrição, irrigação e espaçamento, visando minimizar o microclima favorável ao desenvolvimento de patógeno, são essenciais para o controle do tombamento de mudas causado por $S$. rolfsii, bem como dos demais patógenos.

\section{CONCLUSÕES}

As espécies florestais, nativas ou exóticas, avaliadas são hospedeiras de $S$. rolfsi. Além disso, o patógeno foi capaz de causar o tombamento de mudas dessas espécies em pré e, ou, em pós-emergência, em maior ou menor intensidade, dependendo das características da semente.

\section{REFERÊNCIAS}

ALBREGTS, E. E.; GILREATH, J. P.; CHANDLER, C. K. Soil solarization and fumigant alternatives to bromide for strawberry fruit production. Soil and Crop Science Society of Florida Proceedings, v.55, n.1, p.16-20, 1996.

Alfenas, A. C. et el. Clonagem e doenças do eucalipto. Viçosa, MG: Universidade Federal de Viçosa, 2004. 442p.

AUER, C. G.; GRIGOLETTI Jr., A.; SANTOS, Á. F. Doenças em pinus: identificação e controle. Colombo: Embrapa Florestas, 2001. 28p. (Circular Técnica, 480)

AYCOCK, R. Stem rots and other diseases caused by Sclerotium rolfsii. North Caroline: Agricultural Experiment Station, 1966. 202p. (Technial Bulletin, 174)

CARVALHO, P. E. R. Espécies florestais brasileiras: recomendações silviculturais, potencialidades e uso da madeira. Colombo: Empresa Brasileira de Pesquisa Agropecuária; Centro Nacional de Pesquisa de Florestas; Brasília: Embrapa - SPI, 1994. 640p.

R. Árvore, Viçosa-MG, v.31, n.4, p.629-634, 2007 
CHEN, Y.; KATAN, J. Effect of solar heating of soils by transparent polyethylene mulching on their chemical properties. Soil Science, v.30, n.2, p.271-277, 1980.

DURIGAN, G. et al. Sementes e mudas de árvores tropicais. São Paulo: Páginas \& Letras, 1997. 65p.

FERREIRA, F. A. Patologia florestal: principais doenças florestais no Brasil. Viçosa, MG: SIF, Universidade Federal de Viçosa, 1989. 570p.

GHINI, R. A solar collector for soil disinfestations. Netherlands Journal of Plant Pathology, v.99, n.1, p.45-50, 1993.

GHINI, R.; BETTIOL, W. Coletor solar para desinfestação de substratos. Summa Phytopathologica, v.17, n.3, p.281-287, 1991.

KATAN, J. Solar heating (solarization) of soil for control of soilborne pests. Annual Review of Phytopathology, v.19, p.211-236, 1981.

KATAN, J. Solar pasteurization of soils for disease control: status and prospects. Plant Disease, v.64, n.5, p.450-454, 1980.

LIFSHITZ, R. et al. The effect of sub lethal heating on sclerotia of $S$. rolfsii. Canadian Journal of Microbiology, v.29, n.6, p.1607-1610, 1983.

LORENZI, H. Árvores brasileiras: manual de identificação e cultivo de plantas arbóreas nativas do Brasil. Nova Odessa: Instituto Plantarum, 2002a. v.1

LORENZI, H. Árvores brasileiras: manual de identificação e cultivo de plantas arbóreas nativas do Brasil. Nova Odessa: Instituto Plantarum, 2002b. v.2
LORENZI, H. et al. Árvores exóticas no Brasil: madeireiras, ornamentais e aromáticas. Nova Odessa: Instituto Plantarum, 2003.

MARTINS, M. V. V. et al. Erradicação de escleródios de Sclerotium rolfsii em substratos tratados em coletores solares, em Campos dos Goytacazes - RJ. Revista Brasileira de Fruticultura, v.25, n.3, p.421-424, 2003.

MENDES, M. A. S. et al. Fungos em plantas no Brasil. Brasília: Embrapa-SPI, Embrapa Cenargen, 1998. 569p.

PUNJA, Z. K. The biology, ecology and control of $S$. rolfsii. Annual Review of Phytopathology, v.23, p.97-127, 1985.

PUNJA, Z. K.; JENKINS, S. F. Influence of temperature, moisture, modified gaseous atmosphere, and depth in soil on Sclerotium rolfsii. Phytopathology, v.74, n.6, p.49-754, 1984.

PUNJA, Z. K.; RAHE, J. E. Sclerotium. In: SINGLETON, L. L.; MIHAIL, J. D.; RUSH, C. M. (Eds.). Methods for research on soilborne phytopathogenic fungi. St. Paul: 1992. p.166-170.

RISTAINO, J. B.; PERRY, K. B.; LUMSDEN, R. D. Soil solarization and Gliocladium virens reduce the incidence of southern blight ( $S$. rolfsii) in bell pepper in the field. Biocontrol Science and Technology, v.6, n.4, p.583-593, 1996.

SILVA, G. S. Ocorrência de Sclerotium rolfsii em "neem" (Azadirachta indica). Fitopatologia Brasileira, v.21, n.4, p.522, 1996. 